\title{
Association Between Dioxins/Furans Exposures and Incinerator Workers' Hepatic Function and Blood Lipids
}

\author{
Suh-Woan Hu, PhD \\ Tsun-Jen Cheng, MD, ScD \\ Guo-Ping ChangChien, PhD \\ Chang-Chuan Chan, ScD
}

\section{Learning Objectives}

- Recall the clinical abnormalities reported in epidemiological studies to be more frequent in workers at waste incinerating plants.

- Identify any associations between high or low blood levels of dioxins/furans and altered blood lipid levels.

- Describe the changes in liver enzymes, if any, associated with high exposure of waste-burning workers, and note any interactive effect of dioxins/furans and hepatitis B infection on enzyme levels.

\section{Abstract}

This study examined the effects of dioxins/furans on blood lipids and hepatic function and assessed potential interaction between hepatitis $B$ virus (HBV) infection and dioxins on hepatic function for 133 male workers of municipal waste incinerators. We found that total cholesterol levels in workers with blood dioxins/furans levels of 15.4-59.0 pg TEQ/g lipid (high-exposure workers) averaged $13.5 \mathrm{mg} / \mathrm{dL}$ higher than workers with 5.5-15.3 pg TEQ/g lipid (lowexposure workers). The adjusted odds ratio for total cholesterol abnormality $(>220 \mathrm{mg} / \mathrm{dL})$ was 2.8 (95\% confidence interval $=1.0-7.9)$ between high and low-exposure workers. High-exposure workers showed consistently, although not statistically significantly, higher abnormality in $\gamma$-glutamyltransferase $(>52 \mathrm{U} / \mathrm{L})$, alanine aminotransferase $(>41 \mathrm{U} / \mathrm{L})$, and aspartate aminotransferase $(>37 \mathrm{U} / \mathrm{L})$ than did low-exposure workers. However, there was no statistically significant interaction between dioxins/furans and $\mathrm{HBV}$ on these hepatic enzymes among incinerator workers. (J Occup Environ Med. 2003;45:601-608)

\footnotetext{
From the Institute of Stomatology, Chung Shan Medical University, Taichung, Taiwan (Dr Hu); Institute of Occupational Medicine and Industrial Hygiene, College of Public Health, National Taiwan University, Taipei, Taiwan (Dr Cheng, Dr Chan); and Super Micro Mass Research and Technology Center, Cheng-Shiou Institute of Technology, Kaoshiung, Taiwan (Dr ChangChien).

Chang-Chuan Chan has no commercial interest related to this article.

Address correspondence to: Chang-Chuan Chan, Institute of Occupational Medicine and Industrial Hygiene, College of Public Health, National Taiwan University, Taipei, Taiwan; e-mail: ccchan@ha.mc.ntu.edu.tw.

Copyright $($ by American College of Occupational and Environmental Medicine

DOI: 10.1097/01.jom.0000069243.06498.cf
}

olychlorinated dibenzo-para-dioxins (PCDDs) and polychlorinated dibenzofurans (PCDFs) are ubiquitous in the environment and are emitted mainly from waste incineration, metal smelting, paper pulp bleaching, and polychlorinated biphenyl and chlorophenols production. ${ }^{1,2}$ Studies have shown that workers of municipal waste incinerators had significantly elevated lipid-based blood levels of total PCDDs/PCDFs, hexachlorinated dibenzofuran, ${ }^{3,4}$ and 1,2,3,4,6,7,8-heptachlorinated dibenzofuran. ${ }^{5}$ Epidemiologic studies also have found that incinerator workers had higher mortality of ischemic heart disease ${ }^{6}$ and higher prevalence of hypertension ${ }^{7}$ than general population. However, previous studies reported inconsistent results about the association between dioxins exposures and changes in blood lipids and hepatic function. Some studies found that PCDDs/PCDFs and 2,3,7, 8-tetrachlorodibenzo-para-dioxin (2,3,7,8-TCDD) exposures were significantly associated with elevated serum cholesterol, ${ }^{8,9}$ triglyceride, ${ }^{10}$ alanine aminotransferase (ALT), ${ }^{8,11}$ aspartate aminotransferase (AST), ${ }^{8}$ $\gamma$-glutamyltransferase (GGT), ${ }^{11,12}$ and total bilirubin. ${ }^{13}$ By contrast, some studies showed that 2,3,7,8TCDD exposures were not associated with serum cholesterol, ${ }^{10,14,15}$ ALT, AST, or total bilirubin. ${ }^{16}$ The hepatic toxicity of dioxins/furans is a particularly important health issue in Taiwan because there is a potential interaction of viral infection and chemical exposures for Taiwanese 
workers. Taiwan is a well-known area of high prevalence of hepatitis $B$ virus (HBV) infection. The hepatitis B surface antigen (HBsAg) carrier rate in the general population was $15-20 \%$ in $1982 .{ }^{17}$ Chronic HBV infection has been recognized as a major risk factor for hepatocellular carcinoma, ${ }^{18}$ and it was postulated that PCDFs might promote the occurrence of liver tumors in HBV carriers. ${ }^{1}$ The interaction between HBV infection and dioxins/furans exposures on hepatic toxicity, however, has not been reported so far. This epidemiological study on workers at three municipal waste incinerators in Taipei is therefore designed to determine whether exposures to dioxins/furans affect hepatic function and blood lipids, and whether HBV infection interacts with dioxins/furans exposures on hepatic function among incinerator workers in Taiwan.

\section{Materials and Methods}

\section{Study Subjects}

There were 460 employees at the three municipal waste incinerator plants (A, B, and C) in Taipei city, which have maintained operations since 1991, 1994, and 1998, respectively, and have each burned about 900-1800 tons of waste per day. After communicating with directors of the three plants and considering the tight budget for blood dioxin analysis, we randomly selected 43 to 45 male workers who were employed for more than 6 months and worked either in the operation/ control or the maintenance departments from each of the three plants as the study subjects. Among the 133 sampled workers, 131 agreed to participate and yielded a response rate of $98.5 \%$. The two nonrespondents were replaced with two workers randomly selected from the same department. The Institutional Review Board of the College of Public Health, National Taiwan University, approved this study, and a written informed consent was obtained from each participating worker.

\section{Questionnaire Survey}

We conducted a questionnaire survey to collect information regarding each participant's medical history (including hepatitis), smoking and drinking habits, and demographics by personal interviews for 114 workers and self-reporting for another 19 workers who insisted on answering the questionnaire by themselves.

\section{Physical Examination and Blood Chemistry}

All workers received health checkups, including physical examination, history taking, and ultrasonography, by occupational physicians. Diagnosis of fatty liver was done by abdominal ultrasound examination. We also collected $100 \mathrm{~mL}$ of blood from each participant after overnight fasting. We used $20 \mathrm{~mL}$ of these blood samples to perform analyses of blood counts, total cholesterol, triglyceride, total bilirubin, ALT, AST, GGT, HBsAg, and anti-hepatitis $C$ virus antibody. ALT, AST, GGT, total bilirubin, triglyceride, and total cholesterol were analyzed with a Hitachi 7050 autoanalyzer. Enzyme immunoassay (Austria-II, Abbott Lab., Chicago IL) was used to determine the presence or absence of the serum HBsAg and anti-hepatitis $\mathrm{C}$ virus antibody. All tests were performed in the central laboratory of the National Taiwan University Hospital. The reference values of the National Taiwan University Hospital were used to define the clinically abnormal outcomes of biochemical parameters, which were: AST $>37 \mathrm{U} / \mathrm{L}$, ALT $>41 \mathrm{U} / \mathrm{L}$, GGT $>52 \mathrm{U} / \mathrm{L}$, total bilirubin $>1.0 \mathrm{mg} / \mathrm{dL}$, triglyceride $>200 \mathrm{mg} / \mathrm{dL}$, and total cholesterol $>220 \mathrm{mg} / \mathrm{dL}$.

\section{Determination of Blood PCDDs/ PCDFs Concentrations}

We divided the rest of the $80-\mathrm{mL}$ blood samples from each worker into two 40-mL samples and used them for PCDDs/PCDFs analysis. Blood samples from 75 workers were analyzed at the ERGO Forschungsgesellschaft laboratory, a World Health Organization certified laboratory, and another 58 blood samples were analyzed at the Super Micro Mass Research and Technology Center of the Cheng-Shiou Institute of Technology in Taiwan. Blood samples were randomly assigned to either laboratory. Analytical personnel in both laboratories were not informed of the blood sample's identity and the worker's occupational exposure history. Furthermore, both laboratories analyzed four pairs of randomly selected blood samples in order to assure interlaboratory consistency in PCDDs/PCDFs analysis. The mean coefficients of variation for these four paired blood samples were $3.8 \%$ for total PCDDs, $29.9 \%$ for total PCDFs, and $31.1 \%$ for WHO TEQ.

The following steps were the analytical procedures of PCDDs/PCDFs used by the Super Micro Mass Research and Technology Center. We used $40 \mathrm{~mL}$ of each blood sample to determine lipid-based dioxin levels by an isotope dilution method similar to the US EPA Method 1316 Revision B. ${ }^{19}$ Briefly, lipid contents were determined by extracting the samples three times with ultra pure water, ammonia water, ethanol, ether and petroleum following the CNS 5036N6117 method, which is promulgated by the Central Standard Bureau of Taiwan. The extracted lipids were then spiked with a $20-\mu \mathrm{L}$ standard solution of ${ }^{13} \mathrm{C}$ labeled PCDDs/PCDFs for further cleaning. The cleanup procedures included sulfuric acid washing through sulfuric silica gel, a composite column of sodium silica gel and $40 \%$ sulfuric acid silica gel column, an aluminum column, and an activated carbon column. After cleaning, the concentrated elutant with internal standard solution was prepared for determining and quantifying lipid-based PCDDs/PCDFs by a high-resolution gas chromatography (HRGC), coupled with a high-resolution mass spectrometer (HRMS). The HRGC is a Hewlett Packard 6970 Series gas chromato- 
graph equipped with a DB-5MS (J\&W Scientific, CA) fused silica capillary column (60 m, $0.25 \mathrm{~mm}$ ID, $0.25-\mu \mathrm{m}$ film thickness) and splitless injection. The HRMS is a Micromass Autospec Ultima (UK) mass spectrometer with a positive electron impact $\left(\mathrm{EI}^{+}\right)$source. The valley value defined as $2,3,7,8$ TCDD smaller than $25 \%$ was required and day check verification using the 1613CS3 standard solution was performed every 12 hours. The analysis mode was selected ion monitoring (SIM) at a resolution of 10,000 . The 17 congeners determined are 2,3,7,8TCDD, 1,2,3,7,8-pentachlorinated dibenzodioxin (CDD), 2,3,4,7, 8-hexaCDD, 1,2,3,6,7,8-hexaCDD, 1,2,3,7,8,9-hexaCDD, 1,2,3,4,6,7, 8-heptaCDD, 1,2,3,4,6,7,8,9-octaCDD (OCDD), 2,3,7,8-tetrachlorinated dibenzofuran (TCDF), 1,2,3,7,8-pentaCDF, 2,3,4,7,8-pentaCDF, 1,2,3,4,7,8hexaCDF, 1,2,3,6,7,8-hexaCDF, 1,2,3,7,8,9-hexaCDF, 2,3,4,6,7,8hexaCDF, 1,2,3,4,6,7,8-heptaCDF, 1,2,3,4,7,8,9-heptaCDF, and 1,2,3,4, 6,7,8,9-octaCDF (OCDF). The World Health Organization (WHO) toxic equivalency factors ${ }^{20}$ were used to derive toxic equivalency (TEQ) of 17 congeners for each study subject. For blood samples with specific dioxin or furan levels lower than the limits of detection (LODs), their values were substituted by LODs/square root of $2 .^{21}$

\section{Statistical Analysis}

Data analyses started with classifying workers into dichotomous exposure groups by the median blood dioxins/furans level expressed as the pg-TEQ/g-lipid among 133 participants. The low-exposure group was composed of workers whose dioxins/ furans levels were lower than the median, whereas the high-exposure group consisted of those with dioxins/furans levels higher than the median. The low-exposure group was used as an internal control group in our analysis. The chi-square test, $t$ test, or Wilcoxon rank sum test was used for unadjusted comparisons of the health parameters between these two exposure groups. Stratified analysis was used to assess potential interaction between blood dioxins/ furans and HBV infection on hepatic enzymes. Multiple linear regression models were applied to assess the associations between dioxin exposure groups and continuous parameters of outcomes, controlling for potential confounders. If necessary, natural logarithm transformation was used to enhance normality for outcomes with skewed distribution. AST, ALT, GGT, and total bilirubin were log-transformed for the linear regression analysis. Potential interaction of dioxins/furans exposure and $\mathrm{HBsAg}$ on hepatic function was evaluated by adding an interaction term of "HBsAg $\times$ exposure group" into the regression model. Finally, multiple logistic regression models were used to assess the presence of abnormal outcomes between two exposure groups, adjusting for important confounding factors. Again, an interaction term of "HBsAg $\times$ exposure group" was added to the logistic regression models to assess the presence of statistical interaction. In both multiple linear and logistic regression analyses, the potential confounders to be included in the models were age, duration of employment, incinerator plant, body mass index, cigarette smoking history, alcohol drinking history, and HBsAg status.

We further used tertile and quartile exposure groups to examine the health outcomes that differed significantly between two WHO-TEQbased exposure groups. We also examined the effects of individual congeners on the health outcomes by using dichotomous, tertile, and quartile exposure groups based on the distributions of individual congener's concentrations expressed as $\mathrm{pg} / \mathrm{g}$ lipid. Finally, we treated the blood dioxins/furans level as a continuous variable and used multiple linear regression models in our data analysis. For brevity, only the results derived from dichotomous analysis were presented and discussed in details in this paper.

The statistical software of SAS version 8 (SAS Institute Inc., Cary, NC) was applied for the analyses. An alpha level of 0.05 was used for all statistical tests other than the statistical interaction. We considered the interaction term to be significant at $P$ values less than 0.2 .

\section{Results}

Blood dioxins/furans concentrations, employment history, and health-related characteristics of 133 participants are presented on Table 1 . Blood dioxins/furans levels for these 133 workers ranged from 5.5-59.0 pg TEQ/g lipid, with the median value of $15.3 \mathrm{pg}$ TEQ/g lipid. Workers in the high-exposure group were, on average, 2.5 years older than those in the low-exposure group $(P=0.048)$. Other factors, including duration of employment, history of cigarette smoking or alcohol drinking, HBsAg, anti-hepatitis $\mathrm{C}$ antibody (tested positive for one worker), and body mass index, were not significantly different between two groups. Moreover, distribution of exposure group was not significantly different among three incinerator plants.

Table 2 presents the blood concentrations of the 17 congeners in 133 workers. The levels of $2,3,7,8$ TCDD ranged from nondetectable to $14.0 \mathrm{pg} / \mathrm{g}$ lipid among these workers. Their mean and median concentrations of 2,3,7,8-TCDD were $3.1 \mathrm{pg} / \mathrm{g}$ lipid and $1.6 \mathrm{pg} / \mathrm{g}$ lipid, respectively. Further comparisons revealed that the concentrations of all 17 congeners, except 2,3,7,8-TCDF, 1,2,3,7,8-PentaCDF, 1,2,3,7,8,9HexaCDF and OCDF, in the highexposure group were significantly higher than those in the lowexposure groups $(P<0.01$, Wilcoxon rank sum test; data were not shown in the table).

Comparison of means of hepatic enzymes and blood lipid parameters between two exposure groups are shown on Table 3. Compared with 
TABLE 1

Employment History and Health-Related Characteristics of 133 Workers from Three Municipal Incineration Plants in Taiwan

\begin{tabular}{|c|c|c|c|}
\hline & \multirow[b]{2}{*}{ All workers } & \multicolumn{2}{|c|}{ Dioxins/furan exposure group } \\
\hline & & $\begin{array}{c}\text { Low } \\
\text { (5.5-15.3 pg TEQ/g lipid) }\end{array}$ & $\begin{array}{c}\text { High } \\
\text { (15.4-59.0 pg TEQ/g lipid) }\end{array}$ \\
\hline \multirow{2}{*}{\multicolumn{4}{|c|}{ WHO TEQ, pg/g lipid }} \\
\hline & & & \\
\hline Mean (SD) & $19.6(12.4)$ & $10.3(2.8)$ & $28.9(11.2)^{\star}$ \\
\hline \multicolumn{4}{|l|}{ Age, yr } \\
\hline Mean (SD) & $40.2(7.3)$ & $38.8(7.0)$ & $41.3(7.5) \dagger$ \\
\hline Range & $27.9-55.7$ & $27.9-55.0$ & $28.8-55.7$ \\
\hline \multicolumn{4}{|l|}{ Incineration plant, \% } \\
\hline A & 33.8 & 30.3 & 37.3 \\
\hline B & 33.8 & 42.4 & 25.4 \\
\hline $\mathrm{C}$ & 32.3 & 27.3 & 37.3 \\
\hline \multicolumn{4}{|c|}{ Duration of employment, yr } \\
\hline Mean (SD) & $5.0(3.1)$ & $4.7(2.8)$ & $5.3(3.3)$ \\
\hline Range & $0.6-10.5$ & $0.6-10.5$ & $0.8-10.5$ \\
\hline \multicolumn{4}{|l|}{ Cigarette smoking, \% } \\
\hline Current smoker & 39.9 & 39.4 & 40.3 \\
\hline Former smoker & 9.0 & 6.1 & 11.9 \\
\hline Never & 51.1 & 54.6 & 47.8 \\
\hline \multicolumn{4}{|l|}{ Alcohol drinking, \% } \\
\hline Current drinker & 9.0 & 9.1 & 9.0 \\
\hline Former drinker & 5.3 & 1.5 & 9.0 \\
\hline Never & 85.7 & 89.4 & 82.1 \\
\hline \multicolumn{4}{|c|}{ Drinkers' drinking duration, yr } \\
\hline Mean (SD) & $14.3(6.5)$ & $13.0(6.0)$ & $15.1(6.9)$ \\
\hline \multicolumn{4}{|c|}{ Hepatitis B surface antigen, \% } \\
\hline Positive & 21.1 & 22.7 & 19.4 \\
\hline Negative & 78.9 & 77.3 & 80.6 \\
\hline \multicolumn{4}{|c|}{ Antihepatitis C antibody, \% } \\
\hline Positive & 0.8 & 1.5 & 0 \\
\hline Negative & 99.2 & 98.5 & 100.0 \\
\hline \multicolumn{4}{|c|}{ Body mass index, $\mathrm{kg} / \mathrm{m}^{2}$} \\
\hline Mean (SD) & $24.7(3.8)$ & $24.3(3.7)$ & $25.2(3.9)$ \\
\hline
\end{tabular}

${ }^{*} P<0.05$, Wilcoxon rank sum test.

$\dagger P<0.05$, two-sided $t$ test.

the low-exposure group, mean GGT, total bilirubin, and triglyceride levels in the high-exposure group were slightly, though not statistically significantly, higher than those in the low-exposure group. Compared with the high-exposure group, the AST and ALT levels in the low-exposure group were slightly higher. For the blood lipid parameters, only total cholesterol levels were significantly different between two exposure groups $(P<0.05)$, with a mean level of $199.0 \mathrm{mg} / \mathrm{dL}$ in the high-exposure group workers and a mean level of $184.0 \mathrm{mg} / \mathrm{dL}$ in the low-exposure group.

After adjustment for incinerator plant, age, body mass index, cigarette smoking, and alcohol drinking history in the multiple linear regression analysis, the mean level of total cholesterol remained to be significantly higher in the high-exposure group, with a mean difference of $13.5 \mathrm{mg} / \mathrm{dL}$ (standard error $=6.3$ $\mathrm{mg} / \mathrm{dL}, 95 \%$ confidence interval: $1.1-25.8 \mathrm{mg} / \mathrm{dL}$; Table 4). The other hepatic and blood lipid parameters were not significantly different between two exposure groups, nor were they consistently higher in either group (Table 4). We only presented the results of the models without the interaction term in the table because the interaction term of HBsAg and exposure group was not statistically significant (all $P>0.3$ ). We further explored the relationship between total cholesterol levels and each of the
17 congeners using dichotomous exposure groups in multiple linear regression models. The results showed that higher levels of 2,3,7,8-TCDD, 1,2,3,6,7,8-HexaCDD, 1,2,3,7,8,9HexaCDD, 1,2,3,6,7,8-HexaCDF, and 1,2,3,4,7,8,9-HeptaCDF (all $P<$ $0.05)$ were associated with increased total cholesterol among incinerator workers (data were not shown in the table). However, we observed no significant associations between dioxins/furans exposures and total cholesterol levels when workers' dioxins/furans levels were classified into three or four exposure groups or coded as a continuous variable in our analysis.

Prevalence of HBV infection and abnormality in blood lipids and he- 


\section{TABLE 2}

Blood Concentrations (pg/g, Lipid Based) of 17 Congeners

\begin{tabular}{lcrc}
\multicolumn{1}{c}{ Dioxins/furans } & Mean (SD) & Median & Range \\
\hline 2,3,7,8-TCDD & $3.1(3.2)$ & 1.6 & ND-14.0* \\
1,2,3,7,8-PentaCDD & $5.5(4.5)$ & 4.2 & ND-24.9 \\
1,2,3,4,7,8-HexaCDD & $3.6(2.8)$ & 2.5 & ND-12.6 \\
1,2,3,6,7,8-HexaCDD & $25.2(16.6)$ & 20.3 & $4.9-74.5$ \\
1,2,3,7,8,9-HexaCDD & $8.8(8.8)$ & 3.9 & ND-38.4 \\
1,2,3,4,6,7,8-HeptaCDD & $41.0(29.6)$ & 36.9 & ND-206.1 \\
OCDD & $396.6(275.5)$ & 330.0 & $65.8-1754.7$ \\
2,3,7,8-TCDF & $1.9(2.3)$ & 1.3 & ND-14.9 \\
1,2,3,7,8-PentaCDF & $1.7(2.8)$ & 0.7 & ND-13.9 \\
2,3,4,7,8-PentaCDF & $9.3(6.8)$ & 7.5 & ND-46.9 \\
1,2,3,4,7,8-HexaCDF & $5.7(3.3)$ & 5.2 & ND-23.9 \\
1,2,3,6,7,8-HexaCDF & $5.2(3.5)$ & 4.2 & ND-24.1 \\
1,2,3,7,8,9-HexaCDF & $3.6(5.1)$ & 1.8 & ND-26.1 \\
2,3,4,6,7,8-HexaCDF & $3.8(8.7)$ & 1.8 & ND-97.6 \\
1,2,3,4,6,7,8-HeptaCDF & $16.3(29.8)$ & 12.2 & ND-343.8 \\
1,2,3,4,7,8,9-HeptaCDF & $2.6(5.7)$ & 2.1 & ND-63.1 \\
OCDF & $21.0(52.3)$ & 13.3 & ND-605.6 \\
Total PCDD & $483.7(300.6)$ & 417.5 & $81.4-1890.1$ \\
Total PCDF & $70.0(102.9)$ & 54.1 & $23.5-1202.2$ \\
Total PCDD/PCDF & $553.8(341.3)$ & 479.0 & $107.5-2280.0$ \\
WHO-TEQ & $19.6(12.4)$ & 15.3 & $5.5-59.0$ \\
\hline
\end{tabular}

* ND, not detectable. For those blood samples with nondetectable value for a specific dioxin or furan, the detection limit of the specific congener divided by the square root of 2 was used in the calculation of mean and standard deviation of blood dioxins and furans for all workers.

\section{TABLE 3}

Comparisons ${ }^{*}$ of Hepatic Enzymes and Blood Lipid Parameters Between High and Low Blood Dioxins/Furans Exposure Groups Among Incinerator Workers

Dioxin/furan exposure group

\begin{tabular}{|c|c|c|}
\hline \multirow[b]{2}{*}{ Parameter } & \\
\hline & $\begin{array}{c}\text { Low } \\
\text { (5.50-15.3 pg TEQ/g lipid) }\end{array}$ & $\begin{array}{c}\text { High } \\
\text { (15.4-59.0 pg TEQ/g lipid) }\end{array}$ \\
\hline$n$ & 66 & 67 \\
\hline $\begin{array}{l}\text { Aspartate aminotransferase, } \mathrm{U} / \mathrm{L} \\
\text { mean (SD) }\end{array}$ & $25.5(25.0)$ & $24.2(13.2)$ \\
\hline $\begin{array}{l}\text { Alanine aminotransferase, } \mathrm{U} / \mathrm{L} \\
\text { mean (SD) }\end{array}$ & $37.1(49.4)$ & 35.4 (28.2) \\
\hline $\begin{array}{l}\gamma \text {-Glutamyltransferase, } \mathrm{U} / \mathrm{L} \\
\text { mean (SD) }\end{array}$ & $37.6(32.4)$ & $43.0(39.8)$ \\
\hline $\begin{array}{l}\text { Total bilirubin, } \mathrm{mg} / \mathrm{dL} \\
\text { mean (SD) }\end{array}$ & $0.7(0.3)$ & $0.8(0.3)$ \\
\hline $\begin{array}{l}\text { Triglyceride, mg/dL } \\
\text { mean (SD) }\end{array}$ & 142.1 (98.9) & 147.6 (81.2) \\
\hline $\begin{array}{l}\text { Total cholesterol, } \mathrm{mg} / \mathrm{dL} \\
\text { mean (SD) }\end{array}$ & $184.0(33.4)$ & $199.0(38.1) \dagger$ \\
\hline
\end{tabular}

* Wilcoxon rank-sum test for variables not distributing normally in both original form or after natural logarithm transformation; $t$ test for variables with normal distribution in original form or after natural logarithm transformation.

$\dagger P<0.05$, two-sided t test.

patic enzymes for two exposure groups are presented in Table 5. Abnormality in total cholesterol levels was significantly more prevalent in the high-exposure group than that in the low group $(P=0.037)$. Although the prevalence of fatty liver and the abnormal frequencies of total bilirubin, ALT, AST, GGT, and triglyceride were not significantly dif- ferent between two exposure groups, they were consistently higher in the high-exposure group than in the lowexposure group. By contrast, history of hepatitis was more prevalent in the low-exposure group than in the high group.

As shown in Table 6, the HBsAg positive workers appeared to have consistently higher odds ratios of the dioxins/furans exposures on the abnormal frequencies of ALT, AST, and GGT than the HBsAg negative workers. The comparisons of their odds ratios were 1.78 versus 1.06 for ALT, 1.95 versus 1.28 for AST, and 1.78 versus 1.17 for GGT, respectively. However, the Breslow-Day test for homogeneity indicated that these odds ratios were not significantly different between the two HB$\mathrm{sAg}$ infection groups $(P>0.6)$. These results implied there was no statistically significant interaction between HBV infection and dioxins on inducing abnormal hepatic functions under current dioxins/furans exposures.

As shown in Table 7, multivariable logistic regression analyses did not find significantly higher abnormal frequency of any hepatic enzymes or triglyceride for the highexposure group compared with the low-exposure group. Abnormality in total cholesterol in the high-exposure group was marginally higher than that in the low-exposure group (odds ratio $=2.8 ; 95 \%$ confidence interval: 1.0-7.9). Our multivariable logistic regression models further confirmed no statistically significant interaction (on a multiplicative scale) between HBsAg status and blood dioxins/ furans exposure group on GGT, AST, and ALT, respectively (all $P>$ $0.4)$. Moreover, because there was a marginally significant association between abnormality in total cholesterol and exposure group, we further examined the effects of individual congeners. Workers with blood levels greater than the median concentrations of 2,3,7,8-TCDD, 1,2,3,6,7,8-HexaCDD, OCDD, and $1,2,3,4,7,8,9-\mathrm{HeptaCDF}$ were more 
likely to have abnormal total cholesterol than those with blood levels lower than the median concentrations $(P<0.05$; data not shown in the table). Such findings were consistent with those from the multiple linear regression analysis.

\section{Discussion}

Our results supported the findings of previous studies, which reported elevated total cholesterol levels in workers with higher blood dioxins/ furans concentrations. ${ }^{8,9}$ In addition to the overall effects by the 17 con- geners, our study further identified that six individual congeners, including 2,3,7,8-TCDD, $1,2,3,6,7,8$ HexaCDD, 1,2,3,7,8,9-HexaCDD, OCDD, 1,2,3,6,7,8-HexaCDF and $1,2,3,4,7,8,9-\mathrm{HeptaCDF}$, were associated with elevated total cholesterol levels and/or abnormality of total cholesterol levels among the highexposure workers. The findings of significant associations between these individual congeners and elevated total cholesterol levels improved the biological plausibility for effects of dioxins/furans exposures

\section{TABLE 4}

Effects of Dioxins/Furans on Hepatic Enzymes and Blood Lipids by Multiple Linear Regression Analyses

\begin{tabular}{|c|c|c|c|}
\hline Outcome & $\begin{array}{l}\text { Parameter estimate } \\
\text { (standard error)* }\end{array}$ & $95 \%$ Confidence interval & $R^{2}$ \\
\hline Aspartate aminotransferase $\dagger$ & $-0.05(0.08) \S$ & $(-0.21,0.11)$ & 0.12 \\
\hline Alanine aminotransferase $\dagger$ & $-0.07(0.10) \S$ & $(-0.26,0.12)$ & 0.32 \\
\hline$\gamma$-Glutamyltransferase $\dagger$ & $-0.06(0.11) \S$ & $(-0.28,0.16)$ & 0.30 \\
\hline Total bilirubin $\dagger$ & $0.07(0.06) \S$ & $(-0.05,0.19)$ & 0.14 \\
\hline Triglyceridef & $0.07(0.09) \S$ & $(-0.11,0.25)$ & 0.27 \\
\hline Total cholesterolł & $13.45(6.32)$ & $(1.06,25.84)$ & 0.13 \\
\hline
\end{tabular}

\footnotetext{
${ }^{*}$ For comparison between high- and low-exposure groups, using the low exposure group as the control.

† Adjusted for incinerator plant, age, body mass index, cigarette smoking history, alcohol drinking history, and hepatitis B surface antigen status. Since the interaction term of "hepatitis B surface antigen status $\times$ dioxin exposure group" was not statistically significant, only the results of the models without the interaction term were presented here.

$\ddagger$ Adjusted for incinerator plant, age, body mass index, cigarette smoking history, and alcohol drinking history.

$\S$ Parameter estimate (standard error) on natural logarithm scale.
}

on blood lipid alteration, whose biological significance was usually not explained by the TEQ values. Therefore, further studies relating specific congeners to different adverse health outcomes among these incinerator workers are strongly recommended.

Because previous studies have reported excessive cardiovascular deaths in 2,3,7,8-TCDD-exposed general population ${ }^{22}$ as well as increased mortality from ischemic heart diseases ${ }^{23,24}$ and circulatory system diseases ${ }^{25}$ among dioxinsexposed workers, our findings also suggested a potential cardiovascular problem for the 19 workers with abnormally high total cholesterol and high dioxins/furans exposures in this study. By determining both highdensity lipoprotein and low-density lipoprotein cholesterol in future follow-up, we may better assess their risks of getting cardiovascular diseases from dioxins/furans exposures.

Although blood dioxins/furans concentrations were not statistically significantly associated with either GGT, ALT, AST, or total bilirubin, our data showed that the unadjusted prevalence of abnormality of these hepatic enzymes were consistently higher in the high dioxins/furans exposure group. We thought the lack of statistically significant associations between dioxins/furans exposures

\section{TABLE 5}

Prevalence of Abnormality* in Liver Enzymes and Blood Lipid Parameters and History of Liver Diseases Between High and Low Blood Dioxin Exposure Groups Among Incinerator Workers

Dioxin/furan exposure group

\begin{tabular}{|c|c|c|}
\hline \multirow[b]{2}{*}{ Parameter } & \\
\hline & $\begin{array}{c}\text { Low } \\
\text { (5.50-15.3 pg TEQ/g lipid) }\end{array}$ & $\begin{array}{c}\text { High } \\
\text { (15.4-59.0 pg TEQ/g lipid) }\end{array}$ \\
\hline$n$ & 66 & 67 \\
\hline Fatty liver, \% & 45.5 & 53.7 \\
\hline Aspartate aminotransferase (>37 U/L), \% & 7.6 & 10.1 \\
\hline Alanine aminotransferase (>41 U/L), \% & 18.2 & 20.9 \\
\hline$\gamma$-Glutamyltransferase (>52 U/L), \% & 19.7 & 23.9 \\
\hline Total cholesterol (>220 mg/dL), \% & 13.6 & $28.4 \dagger$ \\
\hline
\end{tabular}

\footnotetext{
* Using the reference values defined by the hospital laboratory where blood samples were analyzed. Aspartate aminotransferase: $>37 \mathrm{U} / \mathrm{L}$; alanine aminotransferase: $>41 \mathrm{U} / \mathrm{L} ; \gamma$-glutamyltransferase: $>52 \mathrm{U} / \mathrm{L}$; total bilirubin: $>1.0 \mathrm{mg} / \mathrm{dL}$; triglyceride: $>200 \mathrm{mg} / \mathrm{dL}$; total cholesterol: $>220 \mathrm{mg} / \mathrm{dL}$.

$\dagger P<0.05$, chi square test.
} 
TABLE 6

Stratified Analysis for Assessing the Interaction Between Dioxins/Furans Exposure and Hepatitis B Surface Antigen Status on ALT, AST, and GGT

\begin{tabular}{|c|c|c|c|c|}
\hline & \multirow{2}{*}{\multicolumn{2}{|c|}{$\begin{array}{c}\text { HBsAg negative } \\
(n=105) \\
\begin{array}{c}\text { Dioxins exposure } \\
\text { group }\end{array}\end{array}$}} & \multirow{2}{*}{\multicolumn{2}{|c|}{$\begin{array}{l}\text { HBsAg positive } \\
(n=28) \\
\begin{array}{c}\text { Dioxins exposure } \\
\text { group }\end{array}\end{array}$}} \\
\hline & & & & \\
\hline & High & Low & High & Low \\
\hline \multicolumn{5}{|c|}{ ALT abnormality (>41 U/L) } \\
\hline Yes & 10 & 9 & 4 & 3 \\
\hline No & 44 & 42 & 9 & 12 \\
\hline Odds ratio & \multicolumn{2}{|c|}{1.06} & \multicolumn{2}{|c|}{1.78} \\
\hline \multicolumn{5}{|c|}{ AST abnormality (>37 U/L) } \\
\hline Yes & 4 & 3 & 3 & 2 \\
\hline No & 50 & 48 & 10 & 13 \\
\hline Odds ratio & \multicolumn{2}{|c|}{1.28} & \multicolumn{2}{|c|}{1.95} \\
\hline \multicolumn{5}{|c|}{ GGT abnormality (>52 U/L) } \\
\hline Yes & 12 & 10 & 4 & 3 \\
\hline No & 42 & 41 & 9 & 12 \\
\hline Odds ratio & \multicolumn{2}{|c|}{1.17} & \multicolumn{2}{|c|}{1.78} \\
\hline
\end{tabular}

ALT, alanine aminotransferase; AST, aspartate aminotransferase; GGT, $\gamma$-glutamyltransferase.

\section{TABLE 7}

Effects of Dioxins/Furans on Abnormal Liver Enzymes, Blood Lipids, and Fatty Liver by Multiple Logistic Regression Analysis

\begin{tabular}{|c|c|c|}
\hline Outcome & Odds ratio* & $\begin{array}{c}\text { 95\% confidence } \\
\text { interval }\end{array}$ \\
\hline Fatty liver† & 1.6 & $(0.7,3.6)$ \\
\hline Aspartate aminotransferase $\dagger$ & 1.3 & $(0.3,4.9)$ \\
\hline Alanine aminotransferase $\dagger$ & 1.2 & $(0.4,3.3)$ \\
\hline$\gamma$-Glutamyltransferase $\dagger$ & 0.8 & $(0.3,2.3)$ \\
\hline Total bilirubin $\dagger$ & 1.9 & $(0.6,5.7)$ \\
\hline Triglyceride $\ddagger$ & 1.5 & $(0.5,4.3)$ \\
\hline Total cholesterolł & 2.8 & $(1.0,7.9)$ \\
\hline
\end{tabular}

${ }^{*}$ For comparison between high- and low-exposure groups using low-exposure group as the control.

† Adjusted for incinerator plant, age, body mass index, cigarette smoking history, alcohol drinking history, and hepatitis B surface antigen status. Because the interaction term of "hepatitis B surface antigen status $\times$ dioxin exposure group" was not statistically significant, only the results of the models without the interaction term were presented here.

$\ddagger$ Adjusted for incinerator plant, age, body mass index, cigarette smoking history, and alcohol drinking history.

and hepatic function in this study could be attributed to the following four reasons. First, the blood dioxins/ furans concentrations were relatively low in this study (with a median of $15.3 \mathrm{pg} / \mathrm{g}$ lipid and range of 5.5-59.0 $\mathrm{pg} / \mathrm{g}$ lipid in WHO TEQ) compared with those in the study of Triebig et al (with a median of $42 \mathrm{ppt}$ and range of 13-281 ppt in international TEQ). ${ }^{8}$ Second, the contrast in blood dioxins/furans levels between the high- and low-exposure groups was relatively small in this study. Third, a relatively small sample size with low statistical power precluded us from detecting small effects. Lastly, the effects might be confounded by other unmeasured incineration-related exposures, such as polycyclic aromatic hydrocarbons, heavy metals, and dioxin-like polychlorinated biphenyls. The joint effects of PCDDs/PCDFs and dioxin-like polychlorinated bi- phenyls on the health parameters could not be evaluated in this study. Therefore, we still could not rule out the possible hepatic effects by dioxins/furans exposures. This issue warranted further investigation because previous studies reported significant associations between dioxins/furans exposures and out-of-range GGT, ${ }^{12,16}$ mean GGT, ${ }^{11}$ nonspecific liver abnormalities, ${ }^{11}$ and $\mathrm{ALT}^{8}$.

This study did not find a statistically significant interaction between dioxins/furans and HBV infection on AST, ALT and GGT in the multiple linear regression and logistic regression analysis although the stratified analysis consistently showed a higher odds ratio for exposure group and abnormality in these three hepatic enzymes, respectively, in $\mathrm{HbsAg-posi-}$ tive workers than in HbsAg-negative workers. Two aspects of this study limited our investigation of potential interaction between $\mathrm{HBsAg}$ and dioxins/furans exposure. First, low dioxins/furans exposure levels and small sample size made the effect estimates imprecise after inclusion of multiple factors in the regression analysis. Second, the HBV infection stages of the HBsAg positive workers might not be the same, and chronic HBV infection did not alter ALT during the whole clinical pathological process. ${ }^{26}$ Future study of a large number of subjects with specific HBV infection stages and higher dioxins/furans exposures can better clarify the statistical interaction of HBV infection and dioxins/ furans on hepatic enzymes.

In conclusion, male incinerator workers with blood dioxins/furans levels of $15.4-59.0 \mathrm{pg}$ TEQ/g lipid had significantly elevated total cholesterol levels. There was no statistically significant interaction between hepatitis B infection and dioxins/ furans exposure on hepatic enzymes.

\section{Acknowledgment}

This study was partially supported by a grant from the Environmental Protection Bureau of Taipei City, Taiwan. 


\section{References}

1. McGregor DB, Partensky C, Wilbourn J, et al. An IARC evaluation of polychlorinated dibenzo-p-dioxins and polychlorinated dibenzofurans as risk factors in human carcinogenesis. Environ Health Perspect. 1998;106(Suppl 2):755-760.

2. Brouwer A, Ahlborg UG, van Leeuwen FXR, et al. Report of the WHO working group on the assessment of health risks for human infants from exposure to PCDDs, PCDFs and PCBs. Chemosphere. 1998;37:1627-1643.

3. Schecter AJ, Malkin R, Papke O, et al. Dioxin levels in blood of municipal incinerator workers. Med Sci Res. 1991;19: 331-332.

4. Schecter A, Papke O, Ball M, et al. Dioxin concentrations in the blood of workers at municipal waste incinerators. Occup Environ Med. 1995;52:385-387.

5. Kumagai S, Koda S, Miyakita T, et al. Polychlorinated dibenzo-p-dioxin and dibenzofuran concentration in the serum samples of workers at continuously burning municipal waste incinerators in Japan. Occup Environ Med. 2000;57:204210.

6. Gustavsson P. Mortality among workers at a municipal waste incinerator. Am J Ind Med. 1989;15:245-253.

7. Bresnitz EA, Roseman J, Becker D, et al. Morbidity among municipal waste incinerator workers. Am J Ind Med. 1992;22: 363-378.

8. Triebig G, Werle E, Papke O, et al. Effects of dioxins and furans on liver enzymes, lipid parameters, and thyroid hormones in former thermal metal recycling workers. Environ Health Perspect. 1998;106(Suppl 2):697-700.

9. Martin JV. Lipid abnormalities in workers exposed to dioxin. $\mathrm{Br} J$ Ind Med. 1984;41:254-256.
10. Calvert GM, Wille KK, Sweeney MH, et al. Evaluation of serum lipid concentrations among U. S. workers exposed to 2,3,7,8-tetrachlorodibenzo-p-dioxin. Arch Environ Health. 1996;51:100-107.

11. Michalek JE, Ketchum NS, Longnecker MP. Serum dioxin and hepatic abnormalities in veterans of Operation Ranch Hand. Ann Epidemiol. 2001;11:304-311.

12. Sweeney MH, Calvert GM, Egeland GA, et al. Review and update of the results of the NIOSH medical study of workers exposed to chemicals contaminated with 2,3,7,8-tetracholodibenzodioxin. Teratogenesis Carcinog Mutagen. 1997/1998; 17:241-247.

13. Watanabe $\mathrm{S}$, Kitamura $\mathrm{K}$, Iida $\mathrm{T}$, et al. Health effects of chronic exposure to polychlorinated dibenzo-p-dioxins, dibenzofurans and coplanar PCB in Japan. Proceedings of the 21st International Symposium on Halogenated Environmental Organic Pollutants and POPs, 9-14 September 2001, Gyeongju, Korea.

14. Calvert GM, Wall DK, Sweeney MH, et al. Evaluation of cardiovascular outcomes among U.S. workers exposed to 2,3,7,8-tetrachlorodibenzo-p-dioxin. Environ Health Perspect. 1998;106(Suppl 2):635-643.

15. Watanabe S, Kitamura K, Kikuchi Y, et al. Health effects of chronic exposure to polychlorinated dibenzo-p-dioxins, dibenzofurans and coplanar PCB around municipal waste incinerators. Organohalogen Compounds. 2000;48:199-202.

16. Calvert GM, Hornung RW, Sweeney $\mathrm{MH}$, et al. Hepatic and gastrointestinal effects in an occupational cohort exposed to 2,3,7,8-tetrachlorodibenzo-para-dioxin. JAMA. 1992;267:2209-2214.

17. Huang K-Y, Lin S-R. Nationwide vaccination: a success story in Taiwan. Vaccine. 2000;18:S35-S38.

18. Schafer DF, Sorrell MF. Hepatocellular carcinoma. Lancet. 1999;353:12531257.

19. US EPA. Method 1613: Tetra-Through Octa-Chlorinated Dioxins and Furans by Isotope Dilution HRGC/HRMS. Revision B. EPA 821/B-94-005, 1994.

20. Van den Berg M, Birnbaum L, Bosveld $\mathrm{AT}$, et al. Toxic equivalency factors (TEFs) for PCBs, PCDDs, PCDFs for humans and wildlife. Environ Health Perspect. 1998;106:775-792.

21. Hornung RW, Reed LD. Estimation of average concentration in the presence of nondetectable values. Appl Occup Environ Hyg. 1990;5:46-51.

22. Pesatori AC, Zocchetti C, Guercilena S, et al. Dioxin exposure and non-malignant health effects: a mortality study. Occup Environ Med. 1998;155:126-131.

23. Flesch-Janys D, Berger J, Gurn P, et al. Exposure to polychlorinated dioxins and furans $(\mathrm{PCDD} / \mathrm{F})$ and mortality in a cohort of workers from a herbicideproducing plant in Hamburg, Federal Republic of Germany. Am J Epidemiol. 1995;142:1165-1175.

24. Vena J, Boffetta $\mathrm{P}$, Becher $\mathrm{H}$, et al. Exposure to dioxin and nonneoplastic mortality in the expanded IARC international cohort study of phenoxy herbicide and chlorophenol production workers and sprayers. Environ Health Perspect. 1998; 106(Suppl 2):645-653.

25. Michalek JE, Ketchum NS, Akhtar FZ. Postservice mortality of US air force veterans occupationally exposed to herbicide in Vietnam: 15-year follow-up. Am J Epidemiol. 1998;148:786-792.

26. Chu C-M, Liaw Y-F. Natural history of chronic hepatitis $\mathrm{B}$ virus infection: an immunopathological study. J Gastroenterol Hepatol 1997;12(Suppl):S218S222. 